\title{
KOMPENSASI, MOTIVASI KERJA, DAN LINGKUNGAN KERJA BERPENGARUH TERHADAP LOYALITAS KARYAWAN PADA RAME CAFÉ JIMBARAN SEAFOOD
}

\author{
I Putu Satya Swadarma ${ }^{1}$ \\ I Gusti Salit Ketut Netra ${ }^{2}$ \\ ${ }^{1,2}$ Fakultas Ekonomi dan Bisnis Universitas Udayana (Unud), Bali, Indonesia \\ email: satyaswadarma1@ gmail.com
}

\begin{abstract}
ABSTRAK
Mendapatkan loyalitas dari seseorang bukanlah sesuatu pekerjaan yang mudah untuk dilakukan. Berbanding terbalik dengan kesulitan mendapatkannya, menghilangkan loyalitas seseorang justru menjadi hal yang sangat mudah untuk dilakukan. Perusahaan perlu memperhatikan faktor-faktor yang mempengaruhi loyalitas karyawan. Tujuan penelitian ini adalah untuk mengetahui pengaruh kompensasi, motivasi kerja, dan lingkungan kerja terhadap loyalitas karyawan. Penelitian dilakukan di Rame Cafe Jimbaran Seafood. Sampel sebanyak 40 orang karyawan, dengan metode sampel jenuh. Pengumpulan data melalui kuesioner. Analisis data yang digunakan adalah regresi linier berganda. Kompensasi, motivasi kerja, dan lingkungan kerja berpengaruh positif terhadap loyalitas karyawan. Manajemen sebaiknya lebih memperhatikan kompensasi yang sesuai dengan kinerja karyawan, motivasi yang tinggi, kenyamanan lingkungan kerja, dan menjalin hubungan yang baik dengan karyawan dengan tujuan meningkatkan rasa loyalitas karyawan yang akan memberikan dampak positif terhadap perusahaan.
\end{abstract}

Kata kunci : Kompensasi, Motivasi Kerja, Lingkungan Kerja, dan Loyalitas Karyawan

\begin{abstract}
Getting loyalty from someone is not an easy job to do. Inversely proportional to the difficulty of getting it, eliminating one's loyalty actually becomes a very easy thing to do. Companies need to pay attention to factors that affect employee loyalty. The purpose of this study was to determine the effect of compensation, work motivation, and work environment on employee loyalty. The study was conducted at Rame Cafe Jimbaran Seafood. A sample of 40 employees was employed, using the saturated sample method. Data collection through questionnaires. Analysis of the data used is multiple linear regression. Compensation, work motivation, and work environment have positive effect on employee loyalty. Management should pay more attention to compensation in accordance with employee performance, high motivation, comfort in the work environment, and establish good relationships with employees with the aim of increasing employee loyalty which will have a positive impact on the company.

Keywords: Compensation, Work Motivation, Work Environment, and Employee Loyalty
\end{abstract}




\section{PENDAHULUAN}

Sumber daya manusia merupakan salah satu sumber daya yang cukup penting perannya di dalam suatu perusahaan, disamping sumber daya yang lain seperti modal, material, mesin dalam pendukung suatu perusahan, hal ini karena manusialah yang mengelola sumber daya lainnya yang ada dalam perusahan, sehingga menjadi bermanfaat dan tanpa adanya sumber daya manusia maka sumber daya lainnya menjadi kurang lengkap (Krisnayanti \& Utama, 2018). Dengan adanya sumber daya manusia yang memiliki sifat loyalitas yang tinggi, akan memudahkan suatu perusahaan dalam mencapai tujuannya.

Fuanida (2016) menyatakan bahwa "Loyalitas kerja merupakan pencapaian pelaksanaan kegiatan/pekerjaan oleh seseorang atau karyawan untuk mencapai tujuan organisasi/perusahaan dalam periode waktu tertentu. Dalam hal kaitannya dengan peningkatan loyalitas kerja karyawan diperlukan adanya lingkungan kerja yang baik, disiplin kerja yang tinggi, dan motivasi yang dapat membangkitkan semangat karyawan dalam bekerja. Loyalitas karyawan pada umumnya dipandang sebagai atribut positif yang jelas di tingkat individu dan kolektif. Namun, dalam konteks yang menantang atau disfungsional, karyawan yang loyal dapat terpecah antara loyalitas organisasi dan pribadi mereka menanggapi konflik dan / atau disfungsi sedemikian rupa sehingga kesejahteraan pribadi mereka terancam. Masalah loyalitas karyawan dalam literatur tentang manajemen sumber daya manusia dipelajari secara luas.

Kesetiaan mungkin hanya sesuai dalam hubungan yang membutuhkan pengorbanan, tanpa mengharapkan segala bentuk imbalan, sementara hubungan bisnis tidak mementingkan diri sendiri. Loyalitas karyawan didefinisikan sebagai tindakan sadar demi kepentingan terbaik majikan, bahkan dengan mengorbankan kepentingan mereka sendiri. Oleh karena itu, ini berlaku untuk kegiatan yang melampaui kewajiban yang timbul dari hukum dan etika. Salah satu sarana yang digunakan untuk menimbulkan loyalitas karyayawan terhadap perusahan adalah kompensasi (Pio et al. 2017). Kompensasi merupakan bentuk pembayaran atau imbalan yang diberikan kepada karyawan dan timbul dari dipekerjakannya karyawan. Karyawan tidak akan melakukan pekerjaan tanpa mendapatkan kompensasi yang layak dari perusahaan. Kompensasi merupakan salah satu faktor penting dan menjadi perhatian pada banyak organisasi dalam mempertahankan dan menarik sumberdaya manusia yang berkualitas. Kompensasi adalah seluruh extrinsic rewards yang didapat karyawan dalam bentuk upah, insentif, dan beberapa tunjangan (benefits) (Purba, 2017)

Karyawan dapat melaksanakan tugasnya secara maksimum antara lain ditentukan oleh motivasi yang mendorong karyawan itu bekerja dengan tekun, serta disiplin yang diterapkan sehingga dapat tercapai tujuan perusahaan di bawah kepemimpinan yang dapat menciptakan suasana kondusif terhadap lingkungan kerja tersebut. Setiap karyawan belum tentu bersedia mengerahkan prestasi kerja yang dimilikinya secara optimal, sehingga masih diperlukan adanya pendorong agar seseorang mau menggunakan seluruh potensinya untuk bekerja. Daya dorong tersebut disebut motivasi (Krisnayanti \& Utama, 2018). Salah satu teori yang dikemukakan oleh Abraham Maslow bahwa setiap manusia terdiri atas lima kebutuhan yaitu: kebutuhan secara fisiologis, rasa aman, sosial, penghargaan dan 
aktualisasi diri. Kebutuhan sosial terdiri dari kebutuhan rasa memiliki, kebutuhan untuk diterima dalam kelompok, berinteraksi dan kebutuhan untuk mencintai dan dicintai.

Penelitian yang dilakukan oleh Frempong et al. (2018) menyatakan hasil bahwa jika karyawan memiliki lingkungan kerja yang baik serta kompensasi yang sesuai dala bekerja, maka loyalitas karyawan akan meningkat. Kondisi ideal dalam bekerja tersebut dicapai salah satunya dengan minimnya stres kerja yang dialami karyawan, jadi karyawan dapat dengan nyaman bekerja. Menurut Nisar et al. (2017) salah satu sarana penting pada manajemen sumber daya manusia dalam sebuah organisasi adalah tercapainya loyalitas kerja para karyawan. Loyalitas kerja sebenarnya merupakan keadaan yang sifatnya objektif, dimana dapat dilihat hasil nyatanya selama terjadi aktifitas pekerjaan pada suatu perusahaan.

Rame Café Jimbaran Seafood merupakan perusahaan yang bergerak di bidang kuliner dan mempunyai karyawan pada tahun 2018 sejumlah 40 orang. Perusahaan ini berdiri pada tahun 2014 dan perusahaan Rame Café Jimbaran Seafood beralamat di Jalan Fours Seasons Hotel, Pantai Muaya, Jimbaran, Kuta Selatan, Kabupaten Badung, Bali. Dari wawancara saya dengan karyawan Rame Café Jimbaran Seafood, motivasi karyawan dalam bekerja rata-rata untuk kebutuhan hidup seperti memenuhi kebutuhan yang meliputi sandang, pangan, dan papan. Selain itu motivasi karyawan bekerja adalah untuk dapat memenuhi kebutuhan aktualisasi diri mereka, dimana agar karyawan mampu menjadi lebih baik dan mampu memdapatkan posisi yang terbaik di perusahaan.

\section{Tabel 1.}

Data Turnover Karyawan Rame Cafe Jimbaran Seafood Tahun 2018

\begin{tabular}{llll}
\hline Bulan & Jumlah Karyawan & $\begin{array}{l}\text { Jumlah Karyawan } \\
\text { Keluar }\end{array}$ & Turnover (\%) \\
\hline Januari & 47 & 0 & 0 \\
Februari & 47 & 2 & 4,2 \\
Maret & 45 & 0 & 0 \\
April & 45 & 0 & 0 \\
Mei & 45 & 1 & 2,2 \\
Juni & 44 & 0 & 0 \\
Juli & 44 & 0 & 0 \\
Agustus & 44 & 0 & 0 \\
September & 44 & 2 & 4,5 \\
Oktober & 42 & 1 & 2,3 \\
November & 41 & 1 & 2,4 \\
Desember & 40 & 0 & 0 \\
Jumlah & 40 & 7 & 17,5 \\
\hline
\end{tabular}

Sumber: HRD Rame Café Jimbaran Seafood tahun, 2018

Dari segi kompensasi, tujuan karyawan mau bekerja di perusahaan Rame Café Jimbaran Seafood tersebut karena sebagian besar karyawan hanya ingin 
memenuhi kebutuhan hidup mereka, dimana dengan motivasi yang mereka miliki, mereka dapat menerima kompensasi yang diberikan oleh perusahaan Rame Café Jimbaran Seafood. Dari segi lingkungan kerja fisik, karyawan Rame Café Jimbaran Seafood tidak hanya sekedar bekerja karena mereka punya kenalan atau teman di perusahaan tersebut, melainkan karyawan ingin sungguh-sungguh bekerja demi keluarga ataupun dirinya sendiri, karena di perusahaan Rame Café Jimbaran Seafood tersebut tidak hanya orang lokal jimbaran yang bekerja disana, tetapi banyak orang bukan asli jimbaran yang bekerja di Rame Café Jimbaran Seafood tersebut.

Rame Café Jimbaran Seafood mempunyai masalah dengan loyalitas karyawan. Dimana hampir sering terjadinya keluar masuk antara karyawan di perusahaan Rame Café Jimbaran Seafood tersebut. Selain itu, berdasarkan hasil wawancara, ada beberapa karyawan yang masih datang terlambat ke perusahaan yang dimana seharusnya para karyawaan selalu taat pada peraturan yang ada di Rame Café Jimbaran Seafood tersebut.

Prabawa \& Suwandana (2017) menyatakan perputaran karyawan dikatakan normal berkisar antara 5-10 persen per tahun dan dikatakan tinggi apabila lebih dari 10 persen per tahun. Jika dilihat pada tabel 1. pada tahun 2018 dari total jumlah karyawan 40 orang adalah 17,5 persen. Berdasarkan hal tersebut, tingkat turnover pada Rame Café Jimbaran Seafood pada akhir tahun 2018 dikatakan tinggi karena persentasenya lebih dari 10 persen.

Terdapat berbagai macam faktor yang dapat memperngaruhi loyalitas karyawan, salah satunya adalah faktor kompensasi, dimana dengan memberikan kompensasi yang tinggi dan baik, maka karyawan akan memberikan rasa loyalitasnya kepada sebuah organisasi atau perusahaan. Selain kompensasi, faktor motivasi juga dapat mempengaruhi loyalitas karyawan terhadap sebuah organisasi atau perusahaan, dimana pemberian motivasi yang baik akan membuat karyawan merasa termotivasi dan tentunya karyawan akan memberikan rasa loyalitasnya dengan sepenuh hati kepada sebuah organisasi atau perusahaan.

Selain itu faktor lingkungan kerja yang baik juga dapat membuat timbulnya rasa loyalitas karyawan terhadap perusahaan. Dimana faktor lingkungan kerja akan mempengaruhi kenyamanan seorang karyawan untuk bertahan di sebuah organisasi atau perusahaan. Lingkungan kerja merupakan keadaan yang berada disekitar karyawan yang akan mempengaruhi karyawan dalam menjalankan tugasnya yang diberikan oleh organisasi maupun perusahaan tersebut. Lingkungan kerja yang baik dan nyaman sangat dibutuhkan oleh karyawan karena lingkungan kerja yang baik dan nyaman tersebut akan membuat karyawan senang dalam bekerja sehingga karyawan dapat memberikan rasa loyalitasnya kepada perusahaan.

Tujuan penelitian ini adalah untuk menganalisis pengaruh kompensasi terhadap loyalitas karyawan di perusahaan Rame Café Jimbaran Seafood Kabupaten Badung, menganalisis pengaruh motivasi kerja terhadap loyalitas karyawan di perusahaan Rame Café Jimbaran Seafood Kabupaten Badung dan menganalisis pengaruh lingkungan kerja terhadap loyalitas karyawan di perusahaan Rame Café Jimbaran Seafood Kabupaten Badung. 
Teori yang digunakan dalam penelitian ini adalah Hierarki Kebutuhan Maslow dasarnya manusia itu baik dan menunjukkan bahwa individu memiliki dorongan yang tumbuh secara terus menerusyang memiliki potensi besar. Sistem hirarki kebutuhan, dikembangkan oleh Maslow, merupakan pola yang biasa digunakan untuk menggolongkan motif manusia. Sistem hirarki kebutuhan meliputi lima kategori motif yang disusun dari kebutuhan yang paling rendah yang harus dipenuhi terlebih dahulu sebelum memenuhi kebutuhan yang lebih tinggi (Taormina \& Gao, 2019)

Dalam penelitian Maineldi et al. (2015) memperoleh hasil bahwa kompensasi memiliki hubungan positif signifikan terhadap loyalitas karyawan. tujuan kompensasi yang ingin dicapai adalah untuk, mendapatkan personil yang berkualitas, mempertahankan karyawan yang ada, memastikan keadilan, menghormati perilaku yang diinginkan, mengendalikan biaya, dan memenuhi peraturan hukum. Onsardi \& Abdullah (2017) menyatakan dalam penelitiannya bahwa kompensasi berpengaruh positif langsung terhadap loyalitas karyawan. Ini berarti bahwa semakin besar kompensasi yang diberikan kepada karyawan, maka loyalitas karyawan akan meningkat. Kompensasi memiliki efek positif langsung pada loyalitas karyawan. Ini berarti bahwa semakin besar kompensasi diberikan kepada karyawan maka loyalitas karyawan akan meningkat. Hasil penelitian ini menerima penelitian dukungan oleh Asmawi (2017) yang melakukan penelitian tentang kesetiaan organisasi untuk karyawan.

Kompensasi adalah salah satu elemen penting yang memotivasi karyawan melakukan pekerjaan, dengan pemberian kompensasi yang merata maka karyawan akan termotivasi untuk meningkatkatkan kinerja serta loyalitas terhadap perusahaan (Armanu, 2017). Penelitian yang dilakukan oleh Handayani (2015) menyatakan bahwa variabel kompensasi mempunyai pengaruh yang signifikan terhadap loyalitas kerja karyawan pada PT. Putera Lautan Kumala Lines. Hipotesis ini berarti bahwa semakin tinggi kompensasi yang diberikan kepada karyawan maka semakin tinggi pula loyalitas karyawan tersebut.

Hasil empiris yang menggambarkan bahwa manajemen kepegawaian dan manajemen kompensasi mempengaruhi loyalitas organisasi. Manurung (2017) memberikan penjelasan bahwa hadiah mempengaruhi persepsi karyawan, dan perilaku dalam berbagai cara. Seperti Palwasha (2017) yang mengatakan membayar upah atau kompensasi yang lebih besar, dan anda akan mendapatkan pekerja yang lebih berkualitas dan bermotivasi tinggi yang akan bertahan lama dengan organisasi. Dengan demikian dapat disusun suatu hipotesis yang menjelaskan hubungan antara kompensasi dengan loyalitas karyawan sebagai berikut :

$\mathrm{H}_{1}$ : Kompensasi berpengaruh positif terhadap Loyalitas Karyawan

Pada dasarnya motivasi kerja berperan penting dalam suatu perusahaan. Seperti yang dinyatakan oleh Dhaliwal (2016) motivasi kerja adalah kesediaan untuk mengerahkan upaya tingkat tinggi kearah tujuan organisasi, dikondisikan oleh kemampuan upaya untuk memenuhi beberapa kebutuhan individu. Menurut Sudiardhita et al. (2018) motivasi kerja dianggap sebagai pengaruh yang mendorong karyawan untuk mencapai tujuan dan sasaran tertentu dari organisasi. Mereka juga mendefinisikan motivasi karyawan sebagai ekspresi dari ukuran energy, komitmen, dan kreativitas yang dibawa oleh karyawan perusahaan ke 
pekerjaan mereka. Armanu (2017) Motivasi memiliki pengaruh kuat pada loyalitas, karyawan yang memiliki motivasi yang baik dalam pekerjaan akan berusaha untuk memberikan kinerja terbaik mereka di tempat kerja agar karyawan menjadi lebih setia dan loyal.

Karyawan lebih loyal ketika manajemen puncak atau manajer mereka adalah pemimpin yang baik. Pemimpin yang baik memotivasi karyawan untuk melakukan pekerjaan dengan baik, berjuang untuk keunggulan, atau hanya mengambil tindakan. Manajemen puncak memiliki dampak yang lebih besar pada kepercayaan karyawan daripada gaya manajemen mereka. Demikian juga, memotivasi karyawan untuk melakukan tugas tidak semudah yang kami kira. Akhirnya, beberapa tindakan dan rekomendasi dapat dikembangkan untuk memastikan karyawan puas dan akan menjadi loyal dengan organisasi mereka

Thanos et al. (2015) menyatakan bahwa motivasi secara parsial berpengaruh signifikan teehadap loyalitas karyawan. motivasi merupakan suatu cara bagaimana mendorong gairah kerja bawahan agar mereka mau bekerja keras dengan memberikan semua kemampuan dan keterampilannya untuk mengwujudkan tujuan perusahaan. Dengan demikian dapat disusun satu hipotesis yang menjelaskan hubungan antara motivasi dengan loyalitas karyawan, sebagai berikut :

$\mathrm{H}_{2}$ : Motivasi berpengaruh positif terhadap Loyalitas Karyawan

Dalam penelitian Maineldi et al. (2015) bahwa lingkungan kerja secara parsial berpengaruh signifikan terhadap loyalitas karyawan. Putra \& Sriathi (2018) lingkungan kerja berpengaruh positif dan signifikan terhadap loyalias lingkungan kerja memiliki pengaruh positif terhadap loyalitas karyawan. Hal tersebut disebabkan dengan lingkungan kerja yang nyaman akan membuat pekerja menjadi semangat dalam melakukan pekerjaannya sehari-hari. Kenyamanan dalam bekerja sehari-hari akan membuat pekerja enggan untuk berpindah pekerjaan dan memilih loyal untuk bekerja di suatu organisasi atau perusahaan.

Lingkungan kerja yang baik meningkatkan loyalitas karyawan dan mengembangkan rasa saling memiliki di antara karyawan sehingga lingkungan kerja memiliki hubungan positif dengan loyalitas karyawan yaitu semakin baik lingkungan kerja maka tingkat loyalitas karyawan semakin tinggi, hal ini sesuai dengan penelitian yang dilakukan Maineldi et al. (2015), Amanah et al. (2015), Purba (2017), Kullab \& Kassim (2017) dan Raziq \& Maulabakhsh (2015). Dalam penelitian Putra \& Sriathi (2018) yang berjudul Pengaruh Lingkungan Kerja, Stress Kerja dan Kompensasi terhadap Loyalitas Karyawan pada Inna Bali Heritage Hotel dengan populasi dari penelitian ini adalah 70 orang karyawan, dan sampel dalam penelitian ini menggunakan teknik metode sensus. Sampel penelitian ini berjumlah 70 orang karyawan hotel Inna Bali Heritage Hotel. Alat analisis yang digunakan adalah analisis regresi linier berganda. Memperoleh hasil bahwa lingkungan kerja berhubungan positif signifikan terhadap loyalitas karyawan. Dengan demikian dapat disusun suatu hipotesis yang menjelaskan hubungan antara lingkungan kerja dengan loyalitas karyawan sebagai berikut :

$\mathrm{H}_{3}$ : Lingkungan Kerja berpengaruh positif terhadap Loyalitas Karyawan 


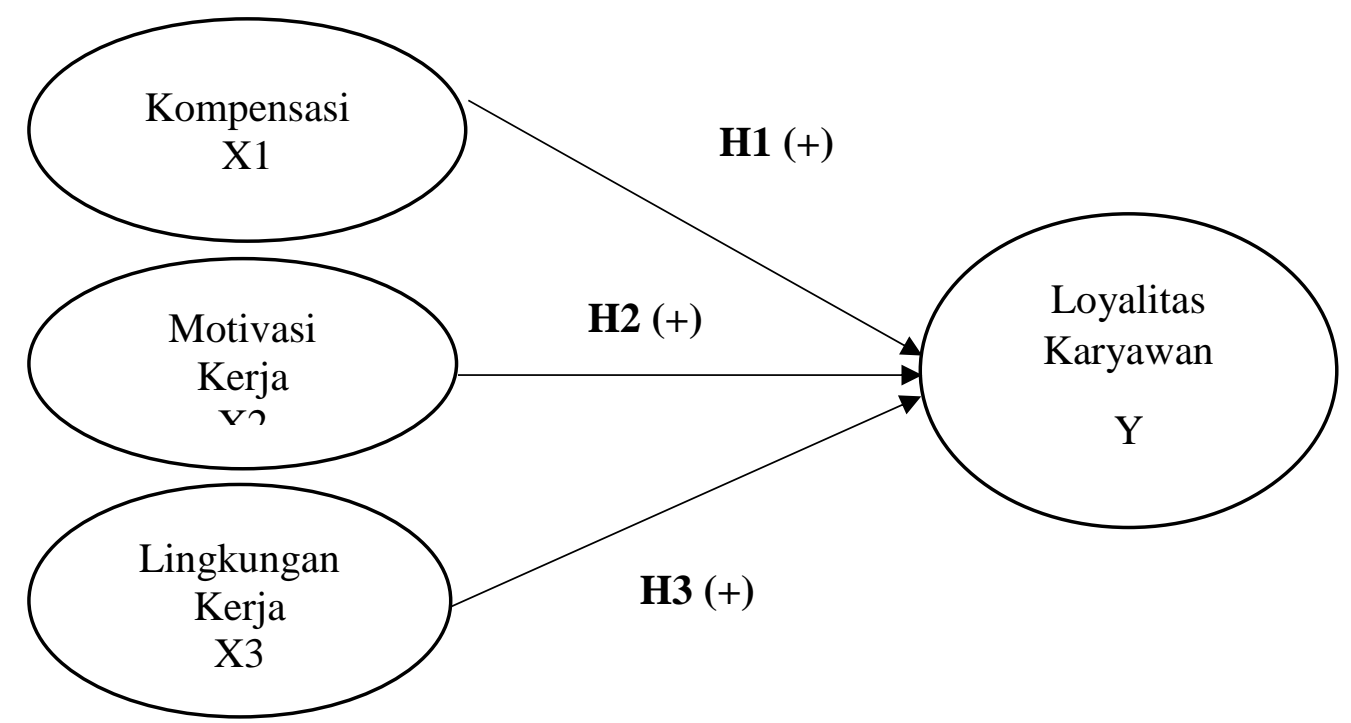

Gambar 1. Kerangka Konseptual

\section{METODE PENELITIAN}

Penelitian ini meggunakan desain kuantitatif kausal. Penelitian ini dilakukan pada Rame Café Jimbaran Seafood yang beralamat di Jalan Fours Seasons Hotel, Pantai Muaya, Jimbaran, Kuta Selatan, Kabupaten Badung, Bali. Obyek dari penelitian ini yaitu kompensasi, motivasi kerja, lingkungan kerja pada loyalitas karyawan pada Rame Café Jimbaran Seafood.Variabel bebas dalam penelitian ini adalah Kompensasi (X1), Motivasi (X2), dan Lingkungan Kerja (X3). Variabel terikat dalam penelitian ini adalah Loyalitas Karyawan (Y).

Indikator loyalitas yang digunakan dalam penelitian ini adalah sebagai berikut: Taat pada peraturan yaitu karyawan wajib mengikuti peraturan yang harus ditaati, Memiliki tanggung jawab pada perusahaan yaitu tanggung jawab yang diberikan perusahaan, Kemauan untuk bekerja sama yaitu kondisi dimana rekan kerja dapat bekerja sama dalam menyelesaikan pekerjaan, Rasa memiliki terhadap keberadaan perusahaan yaitu rasa memiliki karyawan terhadap segala keberadaan perkembangan yang terjadi di perusahaan dan Hubungan antar pribadi yang harmonis di perusahaan yaitu kondisi hubungan antar pekerja di perusahaan.

Kompensasi dalam penelitian ini adalah persepsi karyawan terhadap imbalan atau jasa yang telah diberikan oleh perusahaan kepada para tenaga kerja yang telah memberikan sumbangan tenaga dan pikiran demi kemajuan perusahaan guna mencapai tujuan yang telah ditetapkan.

Motivasi dalam penelitian ini adalah suatu faktor yang dapat mendorong seorang karyawan dalam meningkatkan kinerja didalam perusahaan, motivasi juga merupakan suatu kondisi untuk membangkitkan dan mengarahkan suatu karyawan untuk bekerja lebih baik lagi guna mencapai tujuan dari sebuah perusanaan. Lingkungan kerja dalam penelitian ini adalah lingkungan fisik di mana hal itu memengaruhi kinerja, keamanan, dan kualitas karyawan. Lingkungan kerja 
memberikan keamanan dan memungkinkan karyawan untuk bekerja secara optimal, itu dapat mempengaruhi emosi pekerja.

Data kuantitatif dalam penelitian ini adalah jumlah karyawan serta skor jumlah kuisioner yang telah ditabulasikan dengan pembobotan jawaban responden yang terdiri dari data kompensasi, motivasi, lingkungan kerja, dan loyalitas karyawan. Data kualitatif dalam penelitian ini adalah pernyataan dari responden terhadap kuesioner yang disebarkan di perusahaan Rame Cafe Jimbaran Seafood.Sumber primer yang digunakan dalam penelitian ini adalah berupa kuesioner yang dibagikan ke responden yang merupakan karyawan Rame Cafe Jimbaran Seafood. Sumber sekunder yang digunakan dalam penelitian ini adalah dokumen laporan yang telah dibuat oleh pihak perusahaan Rame Cafe Jimbaran Seafood.

Populasi dalam penelitian ini adalah semua karyawan Rame Cafe Jimbaran Seafood. Responden yang digunakan dalam penelitian ini yaitu jumlah populasi sebesar 40 responden yang merupakan seluruh karyawan Rame Cafe Jimbaran Seafood. Status dari seluruh karyawan yaitu sebagai karyawan tetap. Metode yang digunakan adalah sampel jenuh, dimana semua anggota populasi digunakan sebagail sampel.

Tabel 2.

Jumlah Karyawan Rame Café Jimbaran Seafood Tahun 2018

\begin{tabular}{ccc}
\hline No. & Keterangan Bagian & Jumlah (Orang) \\
\hline 1 & Grill & 8 \\
2 & Kitchen & 8 \\
3 & Bar & 4 \\
4 & Cashier & 3 \\
5 & Hostes & 2 \\
6 & Waiter\&Waitris & 10 \\
7 & Helper & 1 \\
8 & Maintenance & 1 \\
9 & Security & 2 \\
10 & Driver & 1 \\
Total & & $\mathbf{4 0}$ \\
\hline
\end{tabular}

Sumber : HRD Rame Café Jimbaran Seafood,2018

Jumlah karyawan Rame Café Jimbaran Seafood pada tahun 2018 sebanyak 40 orang. Dimana masing-masing karyawan sudah ahli di dalam bidangnya. Data yang dikumpulkan dalam penelitian ini menggunakan metode-metode sebagai berikutWawancara adalah pengumpulan data tanya jawab secara langsung dengan pihak perusahaan mengenai permasalahan yang akan diteliti dan Kuesioner adalah metode pengumpulan data dengan menggunakan daftar pertanyaan yang disebarkan kepada responden mengenai kompensasi, motivasi, lingkungan kerja, dan loyalitas karyawan.

\section{HASIL DAN PEMBAHASAN}

Awal mula berdirinya café yaitu pada tahun 1999, ada salah satu masyarakat jimbaran yang bernama roma, dimana bapak roma tersebut menjual ikan bakar di tepi pantai yang dijual kepada masyarakat lokal. Kondisi warung bapak roma dulu 
masih warung makan biasa. Seiring berjalannya waktu, ada seorang wisatawan yang makan di warung bapak roma, lalu wisatawan tersebut menyarankan bapak roma agar membuka restoran yang lebih bagus dikarenakan jimbaran adalah daerah wisata. Beberapa hari kemudian bapak roma mencoba menyampaikan saran wisatawan tersebut ke kantor desa jimbaran.

Setelah pihak desa mendengar cerita dari bapak roma, desa pun setuju dengan saran yang diberikan wisatawan tersebut dan dibangunlah café di jimbaran, salah satunya Rame Café Jimbaran Seafood. Rame Café jimbaran seafood merupakan usaha yang bergerak dibidang kuliner denga bahan pokok seafood yang kemudian diolah sedemikian rupa agar menarik para konsumen. Desa adat jimbaran merupakan desa yang memiliki mata pencaharian sebagai nelayan, oleh karena itu dikembangkan café dengan bahan pokok seafood. Rame café jimbaran seafood ini dikelola oleh pemilik saham terbesar yaitu Bapak Made Sutarma yang direkomendasikan oleh banjar. Desa jimbaran memiliki 8 banjar yang dimana masing-masing banjar mendapatkan jatah café yaitu sebanyak 4 café. Rame café jimbaran seafood ini beralokasikan di Pantai Muaya Jimbaran, Kuta Selatan, Kabupateng Badung-Bali.

Tabel 3.

Karakteristik Responden Di Rame Café Jimbaran Seafood

\begin{tabular}{|c|c|c|c|c|}
\hline No & Variabel & Klasifikasi & $\begin{array}{l}\text { Jumlah } \\
\text { (orang) }\end{array}$ & $\begin{array}{c}\text { Persentase } \\
(\%)\end{array}$ \\
\hline \multirow{4}{*}{1} & \multirow{4}{*}{$\begin{array}{l}\text { Jenis } \\
\text { Kelamin }\end{array}$} & Laki - Laki & 25 & 62,50 \\
\hline & & Perempuan & 15 & 37,50 \\
\hline & & Jumlah & 40 & 100 \\
\hline & & 18-24 Tahun & 13 & 32,50 \\
\hline \multirow{4}{*}{2} & \multirow{3}{*}{ Usia } & 25-34 Tahun & 14 & 35,00 \\
\hline & & 35-40 Tahun & 10 & 25,00 \\
\hline & & $>40$ Tahun & 3 & 7,50 \\
\hline & \multirow{4}{*}{$\begin{array}{l}\text { Pendidikan } \\
\text { terakhir }\end{array}$} & Jumlah & 40 & 100 \\
\hline \multirow{4}{*}{3} & & SMA/SMK & 25 & 62,50 \\
\hline & & Diploma & 12 & 30,00 \\
\hline & & S1 & 3 & 7,50 \\
\hline & \multirow{4}{*}{ Masa Kerja } & Jumlah & 40 & 100 \\
\hline \multirow{3}{*}{4} & & 1-5 Tahun & 25 & 62,50 \\
\hline & & $>5$ Tahun & 15 & 37,50 \\
\hline & & Jumlah & 40 & 100 \\
\hline
\end{tabular}

Sumber : Data diolah, 2019

Jumlah karyawan Di Rame Café Jimbaran Seafood yang di jadikan sampel sebanyak 40 orang. Jika di lihat dari jenis kelamin, jenis kelamin laki-laki mendominasi dalam penelitian ini dengan persentase sebesar 62,50 persen. Jika di lihat dari usia, yang memiliki usia 25-34 tahun mendominasi dengan presentase sebesar 35 persen. Jika di lihat dari tingkat pendidikan yang memiliki tingkat pendiddikan terakhir SMA/SMK yang mendominasi dengan persentase sebesar 62,50 persen. Jika di lihat dari masa kerja, karyawan yang memiliki masa kerja 1-5 tahun mendimonasi dengan persentase 62,50 persen. 
Tabel 4. menunjukkan bahwa seluruh koefisien korelasi dari indikator variabel yang diuji nilainya lebih besar dari $0,30(\mathrm{r}>0,3)$. Hasil tersebut menunjukkan bahwa seluruh indikator yang terdapat pada penelitian ini terbukti valid.

Tabel 4.

Hasil Uji Validitas

\begin{tabular}{lccc}
\hline No & Variabel & Item Pernyataan & Korelasi Item Total \\
\hline \multirow{4}{*}{1} & X1.1 & 0,826 \\
& \multirow{3}{*}{ Kompensasi } & X1.2 & 0,919 \\
& & X1.3 & 0,912 \\
& & X1.4 & 0,900 \\
& & X2.1 & 0,903 \\
& Motivasi & X2.2 & 0,910 \\
& & X2.3 & 0,891 \\
3 & Xingkungan Kerja & X3.2 & 0,897 \\
& & X3.3 & 0,968 \\
& & X3.4.5 & 0,911 \\
& & X3.6 & 0,953 \\
& & X3.7 & 0,915 \\
4 & Y1.1 & 0,898 \\
& & Y1.2 & 0,955 \\
& & Y1.3 & 0,972 \\
& & Y1.4 & 0,956 \\
& & Y1.5 & 0,846 \\
& & & 0,974 \\
\end{tabular}

Sumber : Data diolah, 2019

Tabel 5.

Hasil Uji Reliabilitas

\begin{tabular}{lc}
\hline \multicolumn{1}{c}{ Variabel } & Cronbach's Alpha \\
\hline Kompensasi (X1) & 0,911 \\
Motivasi (X2) & 0,943 \\
Lingkungan Kerja (X3) & 0,973 \\
Loyalitas Karyawan (Y) & 0,970 \\
\hline Sumber : Data diolah, 2019
\end{tabular}

Tabel 5. menunjukkan masing-masing nilai Cronbach's Alpha pada tiap instrumen tersebut lebih besar dari 0,6 (Cronbach's Alpha > 0,6). Hal tersebut menunjukkan bahwa semua instrumen reliabel sehingga dapat digunakan untuk melakukan penelitian.

Variabel Loyalitas Karyawan yang memiliki rata-rata terendah adalah pernyataan "Saya bertanggung jawab dalam menyelesaikan pekerjaan dengan tepat waktu dan Saya mampu bekerjasama di dalam perusahaan. ", diperoleh nilai rata-rata sebesar 3,25 yang masuk kriteria cukup baik, tetapi memiliki nilai rata-rata yang rendah dibandingkan dengan pernyataan yang lainnya ini berarti secara umum responden belum bertanggung jawab dalam menyelesaikan pekerjaan dengan tepat waktu dan respondenbelum mampu bekerjasama di dalam perusahaan. Variabel Loyalitas Karyawan yang memiliki rata-rata tertinggi adalah pernyataan 
"Saya merasa loyal kepada perusahaan maupun karyawan lainnya.", diperoleh nilai rata-rata sebesar 3,43 yang masuk kriteria baik, ini berarti secara umum responden merasa loyal kepada perusahaan maupun karyawan lainnya.

\section{Tabel 6.}

Deskripsi Jawaban Responden terhadap Loyalitas Karyawan

\begin{tabular}{|c|c|c|c|c|c|c|c|c|c|}
\hline \multirow{3}{*}{ No } & \multirow{3}{*}{ Pernyataan } & \multirow{2}{*}{\multicolumn{5}{|c|}{$\begin{array}{l}\text { Proporsi Jawaban } \\
\text { Responden } \\
\text { (orang) }\end{array}$}} & \multirow{3}{*}{ Jumlah } & \multirow{3}{*}{$\begin{array}{l}\text { Rata- } \\
\text { Rata }\end{array}$} & \multirow{3}{*}{ Kriteria } \\
\hline & & & & & & & & & \\
\hline & & 1 & 2 & 3 & 4 & 5 & & & \\
\hline 1 & $\begin{array}{l}\text { Saya selalu mematuhi } \\
\text { peraturan yang ditetapkan } \\
\text { oleh perusahaan dengan } \\
\text { baik. }\end{array}$ & 2 & 8 & 7 & 20 & 3 & 134 & 3,35 & $\begin{array}{l}\text { Cukup } \\
\text { Baik }\end{array}$ \\
\hline 2 & $\begin{array}{l}\text { Saya bertanggung jawab } \\
\text { dalam menyelesaikan } \\
\text { pekerjaan dengan tepat } \\
\text { waktu. }\end{array}$ & 4 & 7 & 8 & 17 & 4 & 130 & 3,25 & $\begin{array}{l}\text { Cukup } \\
\text { Baik }\end{array}$ \\
\hline 3 & $\begin{array}{l}\text { Saya mampu bekerjasama } \\
\text { di dalam perusahaan. }\end{array}$ & 0 & 10 & 14 & 12 & 4 & 130 & 3,25 & $\begin{array}{c}\text { Cukup } \\
\text { Baik }\end{array}$ \\
\hline 4 & $\begin{array}{l}\text { Saya merasa loyal kepada } \\
\text { perusahaan maupun } \\
\text { karyawan lainnya. }\end{array}$ & 2 & 8 & 6 & 19 & 5 & 137 & 3,43 & Baik \\
\hline 5 & $\begin{array}{l}\text { Saya memiliki hubungan } \\
\text { yang harmonis kepada } \\
\text { karyawan di perusahaan. }\end{array}$ & 2 & 9 & 5 & 21 & 3 & 134 & 3,35 & $\begin{array}{l}\text { Cukup } \\
\text { Baik }\end{array}$ \\
\hline \multicolumn{7}{|c|}{ Rata-rata } & & 3,33 & $\begin{array}{l}\text { Cukup } \\
\text { Baik }\end{array}$ \\
\hline
\end{tabular}

Sumber: Data diolah, 2019

Tabel 7.

Deskripsi Jawaban Responden terhadap Kompensasi

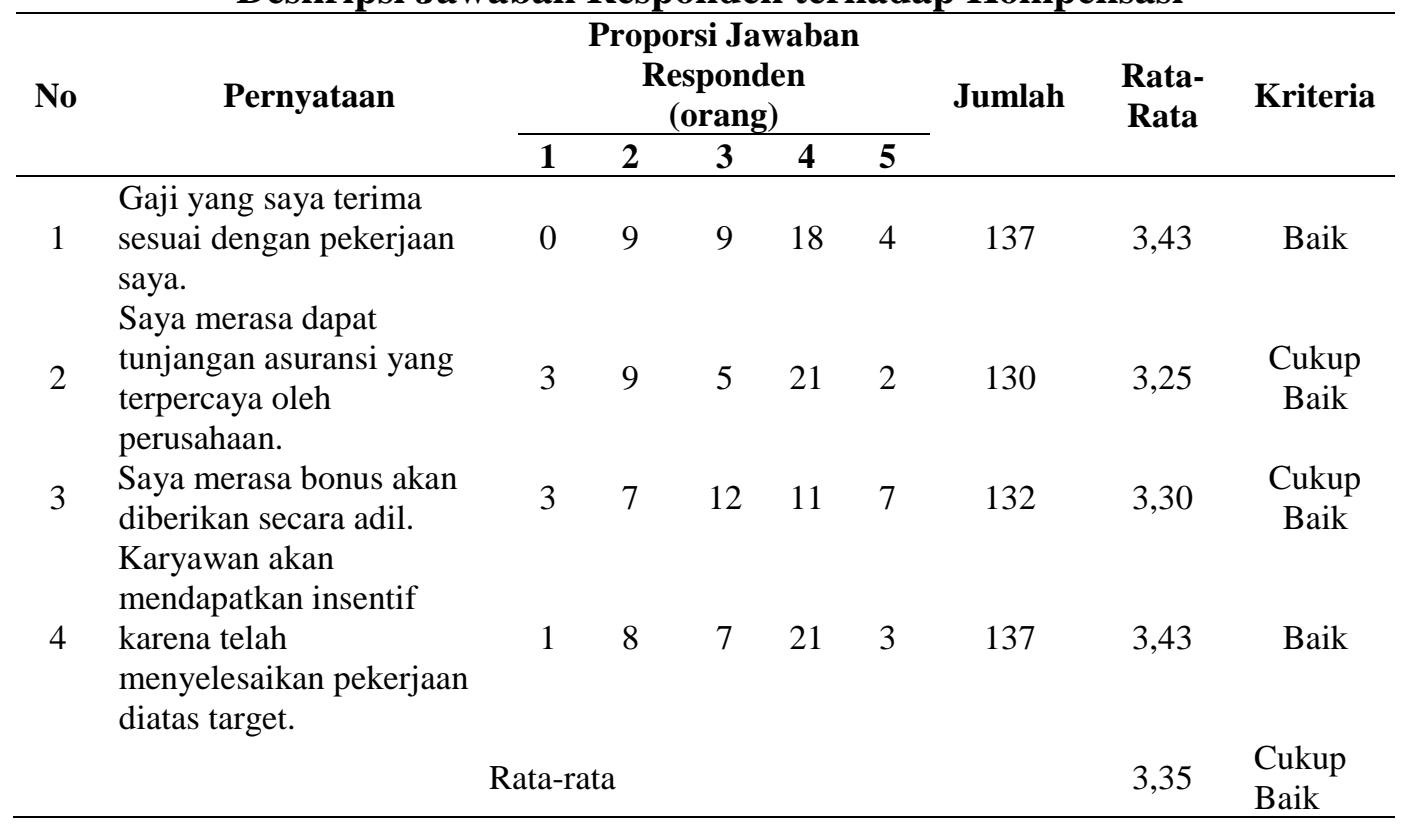

Sumber: Data diolah, 2019 
Variabel Kompensasi yang memiliki rata-rata terendah adalah pernyataan "Saya merasa dapat tunjangan asuransi yang terpercaya oleh perusahaan", diperoleh nilai rata-rata sebesar 3,25 yang masuk kriteria cukup, tetapi memiliki nilai rata-rata yang rendah dibandingkan dengan pernyataan yang lainnya ini berarti secara umum responden menganggap belum merasa dapat tunjangan asuransi yang terpercaya oleh perusahaan. Variabel Kompensasi yang memiliki rata-rata tertinggi adalah pernyataan "Gaji yang saya terima sesuai dengan pekerjaan saya dan Karyawan akan mendapatkan insentif karena telah menyelesaikan pekerjaan diatas target", diperoleh nilai rata-rata sebesar 3,43 yang masuk kriteria baik, ini berarti secara umum responden menganggap gaji yang mereka terima sesuai dengan pekerjaan mereka dan Karyawan akan mendapatkan insentif karena telah menyelesaikan pekerjaan diatas target.

\begin{tabular}{|c|c|c|c|c|c|c|c|c|c|}
\hline \multirow{3}{*}{ No } & \multicolumn{9}{|c|}{$\begin{array}{c}\text { Tabel } 8 . \\
\text { Deskripsi Jawaban Responden terhadap Motivasi }\end{array}$} \\
\hline & \multirow[t]{2}{*}{ Pernyataan } & \multicolumn{5}{|c|}{$\begin{array}{c}\text { Proporsi Jawaban } \\
\text { Responden } \\
\text { (orang) }\end{array}$} & \multirow[t]{2}{*}{ Jumlah } & \multirow[t]{2}{*}{$\begin{array}{l}\text { Rata- } \\
\text { Rata }\end{array}$} & \multirow[t]{2}{*}{ Kriteria } \\
\hline & & 1 & 2 & 3 & 4 & 5 & & & \\
\hline \multirow{5}{*}{$\begin{array}{l}1 \\
2 \\
3\end{array}$} & $\begin{array}{l}\text { Semua karyawan bekerja } \\
\text { sesuai dengan peraturan. }\end{array}$ & 2 & 9 & 6 & 20 & 3 & 133 & 3,33 & $\begin{array}{l}\text { Cukup } \\
\text { Baik }\end{array}$ \\
\hline & $\begin{array}{l}\text { Saya selalu bekerja keras } \\
\text { sesuai dengan target yang } \\
\text { ditetapkan. }\end{array}$ & 2 & 11 & 6 & 18 & 3 & 129 & 3,23 & $\begin{array}{l}\text { Cukup } \\
\text { Baik }\end{array}$ \\
\hline & $\begin{array}{l}\text { Saya memiliki sikap yang } \\
\text { gigih dalam }\end{array}$ & & & & & & & & $\begin{array}{c}\text { Cukup } \\
\text { Baik }\end{array}$ \\
\hline & menyelesaikan tugas. & 1 & 12 & 8 & 16 & 3 & 128 & 3,20 & \\
\hline & \multicolumn{6}{|c|}{ Rata-rata } & & 3,30 & $\begin{array}{l}\text { Cukup } \\
\text { Baik }\end{array}$ \\
\hline
\end{tabular}

Sumber: Data diolah, 2019

Variabel Motivasi yang memiliki rata-rata terendah adalah pernyataan "Saya memiliki sikap yang gigih dalam menyelesaikan tugas.", diperoleh nilai rata-rata sebesar 3,20 yang masuk kriteria cukup, tetapi memiliki nilai rata-rata yang rendah dibandingkan dengan pernyataan yang lainnya ini berarti secara umum responden belum memiliki sikap yang gigih dalam menyelesaikan tugas.. Variabel Motivasi yang memiliki rata-rata tertinggi adalah pernyataan "Semua karyawan bekerja sesuai dengan peraturan.", diperoleh nilai rata-rata sebesar 3,33 yang masuk kriteria cukup baik, ini berarti secara umum Semua karyawan bekerja sesuai dengan peraturan.

Variabel Lingkungan Kerja yang memiliki rata-rata terendah adalah pernyataan "Tata warna di ruangan memberikan suasana yang baik.", diperoleh nilai rata-rata sebesar 3,38 yang masuk kriteria cukup, tetapi memiliki nilai ratarata yang rendah dibandingkan dengan pernyataan yang lainnya ini berarti secara umum Tata warna di ruangan belum memberikan suasana yang baik. Variabel Lingkungan Kerja yang memiliki rata-rata tertinggi adalah pernyataan "Tempat ruangan saya bekerja sudah cukup bersih.”, diperoleh nilai rata-rata sebesar 3,48 
yang masuk kriteria baik, ini berarti secara umum responden menganggap tempat ruangan mereka bekerja sudah cukup bersih.

Tabel 9.

Deskripsi Jawaban Responden terhadap Lingkungan Kerja

\begin{tabular}{|c|c|c|c|c|c|c|c|c|c|}
\hline \multirow[t]{2}{*}{ No } & \multirow[t]{2}{*}{ Pernyataan } & \multicolumn{5}{|c|}{$\begin{array}{c}\text { Proporsi Jawaban } \\
\text { Responden } \\
\text { (orang) } \\
\end{array}$} & \multirow[t]{2}{*}{ Jumlah } & \multirow[t]{2}{*}{$\begin{array}{l}\text { Rata- } \\
\text { Rata }\end{array}$} & \multirow[t]{2}{*}{ Kriteria } \\
\hline & & 1 & 2 & 3 & 4 & 5 & & & \\
\hline 1 & $\begin{array}{l}\text { Penerangan di tempat kerja } \\
\text { saya sudah cukup baik. }\end{array}$ & 0 & 11 & 6 & 17 & 6 & 138 & 3,45 & Baik \\
\hline 2 & $\begin{array}{l}\text { Sirkulasi udara di ruang } \\
\text { bekerja cukup baik. }\end{array}$ & 1 & 9 & 5 & 21 & 4 & 138 & 3,45 & Baik \\
\hline 3 & $\begin{array}{l}\text { Tata warna di ruangan } \\
\text { memberikan suasana yang } \\
\text { baik. }\end{array}$ & 1 & 8 & 9 & 19 & 3 & 135 & 3,38 & $\begin{array}{l}\text { Cukup } \\
\text { Baik }\end{array}$ \\
\hline 4 & $\begin{array}{l}\text { Ruang bekerja di } \\
\text { perusahaan tidak bising. } \\
\text { Tempat ruangan saya }\end{array}$ & 2 & 8 & 5 & 20 & 5 & 138 & 3,45 & Baik \\
\hline 5 & $\begin{array}{l}\text { bekerja sudah cukup } \\
\text { bersih. }\end{array}$ & 1 & 8 & 9 & 15 & 7 & 139 & 3,48 & Baik \\
\hline 6 & $\begin{array}{l}\text { Perusahaan memiliki ruang } \\
\text { kerja yang leluasa }\end{array}$ & 1 & 10 & 6 & 18 & 5 & 136 & 3,40 & $\begin{array}{l}\text { Cukup } \\
\text { Baik }\end{array}$ \\
\hline 7 & $\begin{array}{l}\text { Perusahaan menyediakan } \\
\text { alat pengamanan yang } \\
\text { cukup di dalam } \\
\text { perusahaan. }\end{array}$ & 1 & 9 & 4 & 24 & 2 & 137 & 3,43 & Baik \\
\hline \multicolumn{7}{|c|}{ Rata-rata } & & 3,43 & Baik \\
\hline
\end{tabular}

Sumber : Data diolah, 2019

Tabel 10.

Rangkuman Hasil Analisis Regresi Linear Berganda

\begin{tabular}{|c|c|c|c|c|c|}
\hline \multirow{2}{*}{ Model } & \multicolumn{2}{|c|}{$\begin{array}{l}\text { Unstandardized } \\
\text { Coefficients }\end{array}$} & \multirow{2}{*}{$\begin{array}{c}\begin{array}{c}\text { Standardized } \\
\text { Coefficients }\end{array} \\
\text { Beta } \\
\end{array}$} & \multirow[t]{2}{*}{$\mathbf{T}$} & \multirow[t]{2}{*}{ Sig. } \\
\hline & B & Std. Error & & & \\
\hline (Constant) & $-0,122$ & 0,368 & & $-0,331$ & 0,742 \\
\hline Kompensasi & 0,323 & 0,117 & 0,300 & 2,770 & 0,009 \\
\hline Motivasi & 0,416 & 0,136 & 0,410 & 3,066 & 0,004 \\
\hline Lingkungan Kerja & 0,289 & 0,135 & 0,277 & 2,137 & 0,039 \\
\hline
\end{tabular}

Sumber : Data diolah, 2019

Berdasarkan Tabel 10. dapat ditulis persamaan regresi linear berganda sebagai berikut.

$\mathrm{Y}=-0,122+0,323 \mathrm{X}_{1}+0,416 \mathrm{X}_{2}+0,289 \mathrm{X}_{3}$

Dimana :

$\mathrm{Y}=$ Loyalitas Karyawan

$\mathrm{X}_{1}=$ Kompensasi

$\mathrm{X}_{2}=$ Motivasi

$\mathrm{X}_{3}=$ Lingkungan Kerja 
Nilai constant -0,122 menunjukan apabila Kompensasi, Motivasi dan Lingkungan Kerja bernilai sama dengan 0 (nol) maka Loyalitas Karyawan Di Rame Café Jimbaran Seafood bernilai sebesar -0,122. Dari persamaan regresi linier di atas dapat dijelaskan bahwa kompensasi, motivasi kerja dan lingkungan kerja memiliki pengaruh positif terhadap loyalitas karyawan. Nilai $\beta_{1}$ menunjukan bahwa ada hubungan positif antara kompensasi dengan loyalitas karyawan sebesar 0,323. Nilai $\beta_{2}$ menunjukan bahwa ada hubungan positif antara motivasi kerja dengan loyalitas karyawan sebesar 0,416 . Nilai $\beta_{3}$ menunjukan bahwa ada hubungan positif antara lingkungan kerja dengan loyalitas karyawan sebesar 0,289.

Tabel 11.

Uji Normalitas

\begin{tabular}{lr}
\hline & \multicolumn{2}{c}{ Unstandardized } \\
Residual & 40 \\
N & 0,805 \\
Kolmogorov-Smirnov Z & 0,537 \\
Asymp. Sig. (2-tailed) &
\end{tabular}

Berdasarkan uji normalitas dengan menggunakan One-Sample Kolmogorov-Smirnov Test yang ditampilkan pada Tabel 11. tersebut menunjukkan bahwa besarnya nilai Kolmogorov-Smirnov adalah sebesar 0,537. Nilai Kolmogorov-Smirnov tersebut lebih besar dibandingkan dengan nilai Kolmogorov-Smirnov tabel sebesar 0,05 maka $\mathrm{H}_{\mathrm{o}}$ diterima yang mengindikasikan bahwa data yang digunakan pada penelitian ini terdistribusi normal, sehingga dapat disimpulkan bahwa model memenuhi asumsi normalitas.

Tabel 12.

Uji Multikolinieritas

\begin{tabular}{|c|c|c|}
\hline \multirow{2}{*}{ Variabel } & \multicolumn{2}{|c|}{ Collinearity Statistics } \\
\hline & Tolerance & VIF \\
\hline Kompensasi & 0.638 & 1.567 \\
\hline Motivasi & 0.419 & 2.389 \\
\hline Lingkungan Kerja & 0.447 & 2.239 \\
\hline
\end{tabular}

Sumber : Data diolah, 2019

Berdasarkan Tabel 12. tersebut ditunjukkan bahwa tidak terdapat variabel bebas yang memiliki nilai tolerance kurang dari 0,10 dan juga tidak ada variabel bebas yang memiliki nilai VIF lebih dari 10. Maka dari pada itu model regresi bebas dari gejala multikoleniaritas.

Berdasarkan Tabel 13. tersebut, ditunjukkan bahwa masing-masing model memiliki nilai signifikansi lebih besar dari 5\%. Hal ini menunjukkan bahwa variabel bebas yang digunakan pada penelitian ini tidak berpengaruh secara signifikan terhadap variabel terikatnya yaitu absolute error, maka dari itu, penelitian ini bebas dari gejala heteroskedastisitas. 
Tabel 13.

Uji Heteroskedastisitas (Uji Glesjer)

\begin{tabular}{|c|c|c|c|c|c|}
\hline \multirow{2}{*}{ Variabel } & \multicolumn{2}{|c|}{ Unstandardized Coefficients } & \multirow{2}{*}{$\begin{array}{c}\text { Standardized } \\
\text { Coefficients } \\
\text { Beta } \\
\end{array}$} & \multirow[t]{2}{*}{$\mathbf{t}$} & \multirow[t]{2}{*}{ Sig. } \\
\hline & B & Std. Error & & & \\
\hline (Constant) & 0.444 & 0.247 & & 1.798 & 0.081 \\
\hline Kompensasi & 0.016 & 0.078 & 0.043 & 0.207 & 0.837 \\
\hline Motivasi & 0.051 & 0.091 & 0.142 & 0.559 & 0.580 \\
\hline $\begin{array}{l}\text { Lingkungan } \\
\text { Kerja }\end{array}$ & -0.083 & 0.091 & -0.225 & -0.914 & 0.367 \\
\hline
\end{tabular}

Sumber : Data diolah, 2019

Tabel 14.

Hasil Uji F

\begin{tabular}{llrrrrr}
\hline Model & & Sum of Squares & df & Mean Square & F & Sig. \\
\hline \multirow{3}{*}{1} & Regression & 29.388 & 3 & 9.796 & 32.570 & $0.000^{\mathrm{b}}$ \\
& Residual & 10.827 & 36 & 0.301 & & \\
& Total & 40.215 & 39 & & & \\
\hline
\end{tabular}

Sumber : Data diolah, 2019

Berdasarkan hasil analisis, diketahui nilai signifikansi $\mathrm{F}$ adalah $0,000<0,05$, maka $\mathrm{H}_{0}$ ditolak. Hal ini berarti bahwa variabel Kompensasi $\left(\mathrm{X}_{1}\right)$, variabel Motivasi $\left(\mathrm{X}_{2}\right)$, variabel Lingkungan Kerja $\left(\mathrm{X}_{3}\right)$, secara simultan berpengaruh signifikan terhadap Loyalitas Karyawan (Y) Di Rame Café Jimbaran Seafood, atau model yang digunakan dalam penelitian layak dan dapat dipergunakan untuk analisis berikutnya.

Tabel 15.

Hasil Uji t

\begin{tabular}{|c|c|c|}
\hline Variabel & $\begin{array}{l}\text { Unstandardized Coefficients } \\
\text { Beta }\end{array}$ & Sig. \\
\hline Kompensasi & 0,323 & 0,009 \\
\hline $\begin{array}{l}\text { Motivasi } \\
\text { Lingkungan Keria }\end{array}$ & $\begin{array}{l}0,416 \\
0,289\end{array}$ & $\begin{array}{l}0,004 \\
0,039\end{array}$ \\
\hline
\end{tabular}

Sumber : Data diolah, 2019

Berdasarkan hasil analisis di atas dapat dijelaskan bahwa tingkat signifikansi $0,009<0,05$, sehingga $\mathrm{H}_{0}$ ditolak dan $\mathrm{H}_{\mathrm{a}}$ diterima yang berarti bahwa variabel Kompensasi berpengaruh positif signifikan terhadap Loyalitas Karyawan. Koefisien regresi $\beta 1$ (variabel Kompensasi) sebesar 0,323, menunjukkan bahwa meningkatnya Kompensasi maka akan meningkatkan Loyalitas Karyawan di Rame Café Jimbaran Seafood. Berdasarkan hasil analisis di atas dapat dijelaskan bahwa tingkat signifikansi $0,004<0,05$, sehingga $\mathrm{H}_{0}$ ditolak dan $\mathrm{H}_{\mathrm{a}}$ diterima yang berarti bahwa variabel Motivasi berpengaruh positif signifikan terhadap Loyalitas Karyawan. Koefisien regresi $\beta 2$ (variabel Motivasi) sebesar 0,416, menunjukkan bahwa meningkatnya Motivasi maka akan meningkatkan Loyalitas Karyawan Di Rame Café Jimbaran Seafood. Berdasarkan hasil analisis di atas dapat dijelaskan bahwa tingkat signifikansi 0,039 $<0,05$, sehingga $\mathrm{H}_{0}$ ditolak dan $\mathrm{H}_{\mathrm{a}}$ diterima yang berarti bahwa variabel 
Lingkungan Kerja berpengaruh positif signifikan terhadap Loyalitas Karyawan. Koefisien regresi $\beta 3$ (variabel Lingkungan Kerja) sebesar 0,289, menunjukkan bahwa meningkatnya Lingkungan Kerja maka akan meningkatkan Loyalitas Karyawan Di Rame Café Jimbaran Seafood.

Tabel 16.

Analisis Determinasi

\begin{tabular}{lrrrr}
\hline Model & R & R Square & Adjusted R Square & $\begin{array}{c}\text { Std. Error of the } \\
\text { Estimate }\end{array}$ \\
\hline 1 & $0.855^{\mathrm{a}}$ & 0.731 & 0.708 & 0.54842 \\
\hline
\end{tabular}

Sumber : Data diolah, 2019

Berdasarkan Tabel 16 tersebut dapat diketahui bahwa nilai $r$ square $\left(\left(r^{2}\right)=\right.$ 0,731 Adapun analisis menggunakan rumus sebagai berikut:

$\mathrm{D}=\mathrm{r}^{2} \times 100 \%$.

$\mathrm{D}=0,731 \times 100 \%$

$\mathrm{D}=73,1 \%$

Berdasarkan hasil tersebut diketahui bahwa nilai $\mathrm{R}^{2}=73,1$ persen, yang berarti bahwa sebesar 73,1 persen Loyalitas Karyawan Di Rame Café Jimbaran Seafood dipengaruhi oleh variabel Kompensasi (X1) ,Motivasi (X2), dan Lingkungan Kerja (X3) dan sisanya sebesar 26,9 persen dipengaruhi oleh variabel lain yang tidak diteliti pada penelitian ini.

Berdasarkan pengolahan data SPSS dihasilkan tingkat signifikansi $0,009<$ 0,05. Berdasarkan nilai pengujian tersebut, dapat dilihat dengan statistik bahwa uji jatuh pada penolakan $\mathrm{H}_{0}$ ditolak dan $\mathrm{H}_{1}$ diterima untuk hipotesis pertama. Hal tersebut menyatakan penerimaan hipotesis yang bahwa terdapat pengaruh positif dan signifikan antara Kompensasi terhadap Loyalitas Karyawan di Rame Café Jimbaran Seafood. Koefisien variabel X1 adalah positif 0,323 artinya Kompensasi berpengaruh positif terhadap Loyalitas Karyawan. Apabila Kompensasi meningkat sedangkan Motivasi dan Lingkungan Kerja tetap, maka Loyalitas Karyawan akan meningkat sebesar 0,323. Hasil penelitian ini sesuai dengan penelitian yang dilakukan oleh Manurung (2017) memberikan penjelasan bahwa hadiah mempengaruhi persepsi karyawan, dan perilaku dalam berbagai cara. Seperti Palwasha (2017) yang mengatakan membayar upah atau kompensasi yang lebih besar, dan anda akan mendapatkan pekerja yang lebih berkualitas dan bermotivasi tinggi yang akan bertahan lama dengan organisasi.

Berdasarkan pengolahan data SPSS dihasilkan tingkat signifikansi $0,004<$ 0,05 . Berdasarkan nilai pengujian tersebut, dapat dilihat dengan statistik bahwa uji jatuh pada penolakan $\mathrm{H}_{0}$ ditolak dan $\mathrm{H}_{1}$ diterima untuk hipotesis kedua. Hal tersebut menyatakan penerimaan hipotesis yang bahwa terdapat pengaruh positif dan signifikan antara Motivasi terhadap Loyalitas Karyawan Di Rame Café Jimbaran Seafood .Koefisien variabel X2 adalah positif 0,416, artinya Motivasi berpengaruh positif terhadap Loyalitas Karyawan. Apabila Motivasi meningkat sedangkan Kompensasi dan Lingkungan Kerja tetap, maka Loyalitas Karyawan akan meningkat sebesar 0,416. Hasil penelitian ini sesuai dengan penelitian yang dilakukan oleh Armanu (2017) Motivasi memiliki pengaruh kuat pada loyalitas, 
karyawan yang memiliki motivasi yang baik dalam pekerjaan akan berusaha untuk memberikan kinerja terbaik mereka di tempat kerja agar karyawan menjadi lebih setia dan loyal. Karyawan lebih loyal ketika manajemen puncak atau manajer mereka adalah pemimpin yang baik. Pemimpin yang baik memotivasi karyawan untuk melakukan pekerjaan dengan baik, berjuang untuk keunggulan, atau hanya mengambil tindakan.

Manajemen puncak memiliki dampak yang lebih besar pada kepercayaan karyawan daripada gaya manajemen mereka. Demikian juga, memotivasi karyawan untuk melakukan tugas tidak semudah yang kami kira. Akhirnya, beberapa tindakan dan rekomendasi dapat dikembangkan untuk memastikan karyawan puas dan akan menjadi loyal dengan organisasi mereka. Thanos et al. (2015) menyatakan bahwa motivasi secara parsial berpengaruh signifikan teehadap loyalitas karyawan. motivasi merupakan suatu cara bagaimana mendorong gairah kerja bawahan agar mereka mau bekerja keras dengan memberikan semua kemampuan dan keterampilannya untuk mengwujudkan tujuan perusahaan.

Berdasarkan pengolahan data SPSS dihasilkan tingkat signifikansi 0,039< 0,05. Berdasarkan nilai pengujian tersebut, dapat dilihat dengan statistik bahwa uji jatuh pada penolakan $\mathrm{H}_{0}$ ditolak dan $\mathrm{H}_{1}$ diterima untuk hipotesis kedua. Hal tersebut menyatakan penerimaan hipotesis yang bahwa terdapat pengaruh positif dan signifikan antara Lingkungan Kerja terhadap Loyalitas Karyawan Di Rame Café Jimbaran Seafood Koefisien variabel X3 adalah positif 0,289, artinya Lingkungan Kerja berpengaruh positif terhadap Loyalitas Karyawan. Apabila Lingkungan Kerja meningkat sedangkan Kompensasi dan Motivasi tetap, maka Loyalitas Karyawan akan meningkat sebesar 0,289.

Hasil penelitian ini sesuai dengan penelitian yang dilakukan oleh Maineldi et al. (2015) bahwa lingkungan kerja secara parsial berpengaruh signifikan terhadap loyalitas karyawan. Hal ini sejalan dengan Putra \& Sriathi (2018), Buntak \& Drožđek (2016), Waqas et al. (2015) Zanabazar \& Jigjiddorj (2018), Adedeji \& Ugwumadu (2018), dan Sutanto \& Perdana (2016) bahwa lingkungan kerja memiliki pengaruh positif terhadap loyalitas karyawan. Hal tersebut disebabkan dengan lingkungan kerja yang nyaman akan membuat pekerja menjadi semangat dalam melakukan pekerjaannya sehari-hari. Kenyamanan dalam bekerja sehari-hari akan membuat pekerja enggan untuk berpindah pekerjaan dan memilih loyal untuk bekerja di suatu organisasi atau perusahaan.

Penelitian ini memperoleh implikasi teori dan praktis. Secara teoritis hasil dari penelitian ini menunjukan pengaruh positif signifikan kompensasi, motivasi kerja, dan lingkungan kerja terhadap loyalitas karyawan. Penelitian ini juga dapat menambah kajian empiris dan memperkuat penelitian sebelumnya saat perusahaan ingin meningkatkan loyalitas karyawan. Implikasi praktis yang diperoleh dari penelitian ini adalah Rame Cafe Jimbaran Seafood dapat meningkatkan loyalitas karyawan dengan memperhatikan kompensasi, motivasi kerja, serta lingkungan kerja, namun dapat diperhatikan juga faktor lain yang mempengaruhi retensi karyawan seperti gaya kepemimpinan, dan stress kerja.

\section{SIMPULAN}


Terdapat pengaruh positif dan signifikan antara kompensasi terhadap loyalitas karyawan di Rame Café Jimbaran Seafood. Hal ini berarti semakin tingginya kompensasi, maka akan meningkatkan loyalitas karyawan. Terdapat pengaruh positif dan signifikan antara motivasi kerja terhadap loyalitas karyawan di Rame Café Jimbaran Seafood. Hal ini berarti semakin tingginya motivasi kerja, maka akan meningkatkan loyalitas karyawan. Terdapat pengaruh positif dan signifikan antara lingkungan kerja terhadap loyalitas karyawan di Rame Café Jimbaran Seafood. Hal ini berarti semakin tingginya lingkungan kerja, maka akan meningkatkan loyalitas karyawan.

Berdasarkan hasil yang diperoleh kompensasi, motivasi kerja dan lingkungan kerja memiliki pengaruh yang positif signifikan terhadap loyalitas karyawan di Rame Café Jimbaran Seafood, ini menunjukan bahwa semakin tinggi kompensasi, motivasi kerja dan lingkungan kerja di Rame Café Jimbaran Seafood. Pihak manajemen di Rame Café Jimbaran Seafood harus tetap mempertahankan kompensasi, motivasi kerja dan lingkungan kerja di dalam perusahaan agar karyawan merasa puas dan dapat berkomitmen terhadap perusahaan, sehingga akan meningkatkan loyalitas karyawan di Rame Café Jimbaran Seafood.

Hal yang harus ditingkatkan adalah dari segi kompensasi adalah saya merasa dapat tunjangan asuransi yang terpercaya oleh perusahaaan memiliki rata-rata terendah hal ini harus ditingkatkan lagi agar karyawan merasa semangat dalam bekerja dengan memberikan tunjangan asuransi yang terpercaya. Dari segi motivasi keja hal yang perlu ditingkatkan adalah saya memiliki sikap yang gigih dalam menyelesaikan tugas adapun hal yang dapat dilakukan adalah dengan memberikan pelatihan mengenai ketrampilan karyawan agar karyawan dapat bekerja lebih giat lagi. Dari segi lingkungan kerja hal yang perlu ditingkatkan adalah tata warna di ruangan memberikan suasana yang baik dengan cara memberikan tata warna di ruangan memberikan suasana yang baik, agar karyawan merasa semangat dalam bekerja.

\section{REFERENSI}

Adedeji, A. O., \& Ugwumadu, O. C. (2018). Factors Motivating Employee Loyalty and Employee Retention in Deposit Money Banks in Nigeria. International Journal of Human Resource Studies, 8(3), 300. https://doi.org/10.5296/ijhrs.v8i3.13555

Amanah, L., Fathoni, A., \& Minarsih, M. M. (2015). Pengaruh Lingkungan Kerja , Motivasi dan Perilaku Kepemimpinan Terhadap Loyalitas Karyawan. Journal of Management, 1(1), 1-8.

Armanu. (2017). The Effect Of Direct and Inderect Compensation To Motivation and Loyalty Of The Employee. Management, 1(1), 1-20.

Asmawi, M. (2017). The Effect Of Compensation, Empowerment, And Job Satisfaction On Employee Loyalty. Journal Management, 1(1), 1-20. https://doi.org/10.18535/ijsrm/v5i12.03

Buntak, K., \& Drožđek, I. (2016). Parameters Influencing Employee Loyalty. 
Center for Quality, 1(6), 149-160.

Dhaliwal, A. (2016). Motivation and its impact on organization. International Journal of Scientific Research and Management, 4(6), 4270-4278. https://doi.org/10.18535/ijsrm/v4i6.09

Frempong, L. N., Agbenyo, W., \& Darko, P. A. (2018). The Impact of Job Satisfaction on Employees ' Loyalty and Commitment: A Comparative Study Among Some Selected Sectors in Ghana. European Journal of Business and Management, 10(12), 95-105.

Fuanida, A. (2016). Pengaruh Kompensasi, Stres Kerja, Dan Motivasi Terhadap Loyalitas Kerja Karyawan CV. Sapu Dunia Semarang. Jurnal Ilmu Administrasi Bisnis, 4(6), 128-211.

Handayani, T. (2015). Pengaruh Kompensasi terhadap Kinerja Guru. Utilitas, 1(1), 24-34. Retrieved from http://www.tjyybjb.ac.cn/CN/article/downloadArticleFile.do?attachType=P DF\&id=9987

Krisnayanti, \& Utama, M. (2018). Pengaruh Kompenasi, Mptivasi, dan Lingkungan Kerja terhadap Kualitas Kerja Karyawan PT. Delta Satria Dewata Denpasar. E-Jurnal Manajemen Unud, 7(7), 3915-3943.

Kullab, M. A. M., \& Kassim, R. M. (2017). Determinants of Working Environment , Employee Loyalty and Employee Turnover of ICT- SME Industry. World Journal of Research and Review, 5(5), 6-8.

Maineldi, Hendriani, \& Daulay. (2015). Pengaruh kompensasi dan lingkungan kerja terhadap loyalitas karyawan pada PT. Jatim Jaya Perkasa Kebun Banjar Balam Indragiri HulU. Jom FEKON, 1(2), 1-20.

Manurung. (2017). The Effect Of Direct and Inderect Compensation to Employee's Loyalty: Case Study at Directorate Of Human Resources In PT Pos Indonesia. Journal of Indonesian Applied Economics, 6(1), 84-102.

Nisar, Q. A., Uzair, M., Razzaq, W., \& Sarfraz, M. (2017). Impact of HR Practices on Employee loyalty and commitment: Mediating role of Job satisfaction. International Journal of Management Excellence, 9(2), 1067. https://doi.org/10.17722/ijme.v9i2.347

Onsardi, M. A., \& Abdullah, T. (2017). The Effect Of Compensation, Empowerment, And Job Satisfaction On Employee Loyalty. International Journal of Scientific Research and Management, 05(12), 7590-7599. https://doi.org/10.18535/ijsrm/v5i12.03

Palwasha. (2017). The Impact of Compensation and Promotional Opportunities on Employee Retention in Academic Institutions: The Moderating Role of Work Environment. International Journal of Economic Perspectives, 1(1), 378391. 
Pio, L. O., Johnly, R. R., \& Tampi, J. R. E. (2017). Pengaruh Kompensasi Terhadap Kinerja Karyawan Pt. Bank Tabungan Negara (Persero), Tbk. Kantor Cabang Manado. Jurnal Administrasi Bisnis, 1(1), 1-6.

Prabawa, M. Y., \& Suwandana, I. G. M. (2017). Pengaruh Ketidakamanan Kerja, Kepuasan Kerja dan Komitmen Organisasional Terhadap Turnover Intention Pada Grand Mirage Resort \& Thalasso Bali. E-Jurnal Manajemen Unud, 12(6), 6561-6591.

Purba, B. K. (2017). Pengaruh Kompensasi dan Lingkungan Kerja terhadap Loyalitas Karyawan (Studi Kasus PT. Capella Dinamik Nusantara Cab. Kandis). Jom Fisip, 4(1), 1-12.

Putra, I. W. S., \& Sriathi, A. A. A. (2018). Pengaruh Lingkungan Kerja, Stres Kerja Dan Kompensasi Terhadap Loyalitas Karyawan. E-Jurnal Manajemen $\begin{array}{llll}\text { Universitas } & \text { Udayana, } & 786 .\end{array}$ https://doi.org/10.24843/ejmunud.2019.v08.i02.p08

Raziq, A., \& Maulabakhsh, R. (2015). Impact of Working Environment on Job Satisfaction. Economics and Finance, 23(10), 717-725. https://doi.org/10.1016/s2212-5671(15)00524-9

Sudiardhita, M., Hartono, H., \& Sariwulan, N. (2018). The Effect Of Compensation, Motivation Of Employee and Work Satisfaction to Employee Performance PT. Bank XYZ (Persero) TBK. Academy of Strategic Management Journal, 17(4), 1-20.

Sutanto, E. M., \& Perdana, M. (2016). Antecedents variable of employees loyalty. Jurnal Manajemen \& Kewirausahaan, 18(2), 111-118. https://doi.org/10.9744/jmk.18.2.111

Taormina, R. J., \& Gao, J. H. (2019). Maslow and the motivation hierarchy: Measuring satisfaction of the needs. American Journal of Psychology, 126(2), 155-177. https://doi.org/10.5406/amerjpsyc.126.2.0155

Thanos, C. A., Pangemanan, S. S., \& Rumokoy, F. S. (2015). the Effect of Job Satisfaction and Employee Motivation on Employee Loyalty ( Case Study of Pt Kimia Farma Apotek in Sam Ratulangi, Manado ). Jurnal Berkala Ilmiah Efisiensi, 15(04), 313-321.

Waqas, A., Bashir, U., Sattar, M. F., Abdullah, H. M., Hussain, I., Anjum, W., ... Arshad, R. (2015). Factors Influencing Job Satisfaction and Its Impact on Job Loyalty. International Journal of Learning and Development, 4(2), 141-161. https://doi.org/10.5296/ijld.v4i2.6095

Zanabazar, A., \& Jigjiddorj, S. (2018). Impact of Employees Satisfaction in Employee Loyalty, Retention and Organizational Performance. International Journal of Management and Applied Science, 4(7), 51-55. 